\title{
Cultural Governance in Sustainable Cities
}

\author{
Nancy Duxbury \\ Centre for Social Studies - \\ University of Coimbra
}

ABSTRACT: The paper proposes a three-part system of cultural governance for sustainable cities: culturally sensitive sustainability governance processes and structures, a cultural lens on all public policies/decisions and a sustainability approach to cultural policy/planning and governance.

KEYWORDS: urban cultural policy, urban sustainable development, cultural sustainability, cultural governance.

RESUM: Aquest article proposa un sistema tripartit de governança cultural per a ciutats sostenibles: processos i estructures de governança de la sostenibilitat amb sensibilitat cultural, una òptica cultural en totes les polítiques o decisions públiques i un enfocament sostenible de la política o planificació cultural i de la governança.

Paraules CLAU: política cultural urbana, desenvolupament urbà sostenible, sostenibilitat cultural, governance cultural.

RESUMEN: Este artículo propone un sistema tripartito de gobernanza cultural para ciudades sostenibles: procesos y estructuras de gobernanza de la sostenibilidad con sensibilidad cultural, una óptica cultural en todas las políticas o decisiones públicas y un enfoque sostenible de la política/planificación cultural y de la gobernanza.

Palabras Clave: política urbana cultural, desarrollo urbano sostenible, sostenibilidad cultural, gobernanza cultural. 
Sustainability means more than the protection of the environment; it also requires a long-term vision for catalyzing positive change leading to sustainable social and cultural contexts in relation to the built environment. [...] This vision needs to reflect the distinctive nature and characteristics and identities of each city.

Choi and Ahn (2013: 51)

I $\mathrm{n}$ the context of rapid global urbanization, we face a pressing need to transform urban environments into milieu fostering more holistically sustainable living patterns that address the interrelated environmental, social, economic and cultural issues and dynamics of living together on a finite planet. While there is no consensus on a singular definition of sustainability or sustainable development, in general the definition of sustainable development originally put forward by the Brundtland Commission (1987), while heavily critiqued, continues to guide thinking about urban sustainable development - a sustainable city should meet the needs of the present without compromising the ability of future generations to meet their own needs. The urgent pressure to mitigate climate change and $\mathrm{CO}_{2}$ emissions and address energy needs in the context of 'peak oil' have added an overlay to this vision resulting in prioritization of attention to energy development/use, greenhouse gas reduction and climate change adaptation and mitigation. But social and cultural dynamics emerging from diversifying urban populations, widening social divides and wealth inequities, economic crises and clashes between neoliberal development policies and urban citizens in cities globally point to the need to consider 'urban sustainability' with a broader lens. So while environmental urgencies must remain core in the face of our current climatic crisis, it is evident that urban sustainability must be viewed with a multi-dimensional lens that can also incorporate and address these interrelated issues of human cohabitation, change and development.

As many scholars have pointed out, mainstream views of sustainability do not adequately incorporate "many important factors ... includ[ing] the spiritual and cultural dimensions of man and knowledge" (Shaharir, 2012: 91). However, a new view of sustainability that includes culture is emerging through transdisciplinary research and reflection (e.g., Soini \& Birkeland, forthcoming) and a wide range of experimental policy initiatives and pro- 
jects rooted in public participation (Duxbury \& Jeannotte, 2011). It has been informed by UNESCO's statements on the contributions of cultural diversity to sustainable development, the recovery of historical and culture-specific development approaches and worldviews, and community development trends (Duxbury, Cullen \& Pascual, 2012). A call for a 'cultural lens' and the rise of a 'four-pillar' model of sustainability with four interconnected dimensions - environmental responsibility, economic health, social equity and cultural vitality (Hawkes, 2001) - can be found in writings from many countries. Yet many conceptual and operational challenges remain (see, e.g., Duxbury, Cullen \& Pascual, 2012).

To advance the inclusion of culture into 'sustainable city' public policies and practices, that is, into the frameworks through which urban environments and living conditions are collectively envisioned and constructed, artistic and cultural practices must be recognized as integral to sustainable development and supported in more regularized ways. The systematic inclusion of culture within urban sustainability frameworks must build on both conceptual and practice-based experimental foundations and put forward principles and operational strategies for cultural governance systems that are sympathetic and coherent within evolving thinking about designs and strategies for more sustainable cities and communities. In a modest way, this article aims to address this challenge by beginning to sketch the contours of what systems of cultural governance might look like within a sustainable city context.

\section{Context:Transitioning toward more Sustainable Cities}

Acknowledging that cities are social spaces constituted through the coexistence of multiple publics, cultures and histories (Sandercock, 2003), transforming our cities is rooted in transforming collective perceptions and behaviours. While grossly oversimplifying the matter, this process involves two interlinked dimensions: $(a)$ altering individual and collective ways of thinking and acting, and $(b)$ developing the appropriate organizational/governance frameworks, strategies and physical infrastructure to induce and support such transformations. In both areas, culture can play important roles. 


\section{Altering Ways of Thinking and Acting}

As a process of change, sustainable development is about creating a learning environment in which, as Choi and Ahn (2013) view it, "all participants strive to improve the situation that exists for the needs of today and tomorrow, acknowledging aspirations as well as needs and therefore engaging the drive for change and improvement within society" (p. 51). From a public education perspective, growing attention is being placed on finding communicative approaches and narrative frames to develop new ways of thinking and convince the public of the need to make behavioural changes (ISSC, 2013). Girard (2011) characterizes citizens' capacity to develop and embrace renewed ways of thinking and being, while linking to cultural memory, as cultural resilience:

City cultural resilience is the internal energy, the inner force (or vitality) that allows the city to react to external forces, adapt to them, and conserve its specific identity in the long run, in spite of turbulent transformation processes, and to design new win-win solutions. Cultural resilience stresses the notion of the cultural memory of the community as a formative strength of collective consciousness, foundation of continuity, engine of the future and new actions, in order to improve trust, cooperation and coordination of actions, and to promote a sense of community. [...] Cultural resilience depends on the capacity to think and choose in a systematic, multidimensional, open and relational way, linking short-, medium- and long-term perspectives, with attention to the 'memory' of the system in achieving common interests. (p. 60)

The 'cultural resilience' of a city and its citizens will increasingly be intertwined with the rise of citizen-driven collaborations and activist and artistic actions that critique unsustainable norms and demonstrate different ways of living, thinking and acting (see, e.g., Camponeschi, 2013; Duxbury, 2013, 2014; Kirchberg \& Kagan, 2013; Miles, 2013). Civic governance and infrastructure must be ready to enable these initiatives and to facilitate coalitions and systems of arrangements to sustain actions in the public interest. To embrace this broader view of cultural vitality and resilience, it must be linked to the typical objects of municipal cultural policy: the arts and cultural activities, the organizations and infrastructure supporting them. 


\section{Developing Frameworks, Strategies and Infrastructure for Transformation}

Recognizing that the aims, priorities and processes of development/ transformation differ significantly from locale to locale and among different groups, "the role played by governance in any long-term transition to sustainable development is that of steering an interactive and reflexive process of debate and dialogue" (Jordan 2008: 25). Within the sustainable city, strategy is viewed as:

the capacity to manage the growing complexity of the city as an evolving and dynamic system in constant flux, and solve conflicts with new capacity for synthesis, integrating multiple elements and components, generally considered separated and in conflict/contradiction, and identifying new connections, synergies and relational networks. (Girard, 2011: 61)

As a response to "the limits to rational steering" in governance for sustainable development, policy design techniques such as transition management have emerged (Newig et al., 2007, p. 185). Transition management "combines an orientation toward a long-term vision of 'sustainable development' with short-term experimental learning to probe options and find pathways to realise the vision" (Voß et al., 2009, p. 277). This approach acknowledges that processes of social and ecological reproduction are "non-linear, indeterminate, contextually specific, and attainable through multiple pathways" (NSFwUS, 2000: 7). It also recognizes that goals within each domain of sustainability are contested; that knowledge of the complex dynamics among society, technology and nature is limited; and that power to shape change is distributed across many actors and systems (Newig et al., 2007).

Relations are central in this context, and the governance imperative becomes the development or improvement of relations among various systems to maximize benefits towards human sustainable development (Girard, 2011). City governance thus promotes cooperation and the capacity to coordinate actions of multiple different actors, building a "neural network of connections" (p. 66) and giving to the city "an 'intrinsic' organizational capacity" (p. 58). Successful action is more than meeting specific goals; "it is also about creating an enriched platform for further action" (Silver, 2013: 260). 


\section{Foundations: Diverse Efforts to Include Culture in Sustainability}

Internationally, local authorities have experimented in seeking approaches to incorporate culture into sustainability planning and governance practices. For example, in Canada a national initiative led numerous communities to develop Integrated Community Sustainability Plans (ICSPS) that invented ways to incorporate culture as the fourth pillar of sustainability. Based on participatory citizen-based planning efforts that included local cultural leaders (Jeannotte \& Duxbury, 2012), the ICSPs tend to view local culture(s) as an aspect of the community's self-vision and goals - the essence of the community to be sustained as well as a strategic resource to help the community to achieve its broader civic goals. Such local efforts have been conducted in relative isolation from one another and the contours of these frameworks are just now emerging. The recent launch of an international awards programme by the City of Mexico and UCLG to recognize cultural policies that have best contributed to sustainable development promises to make efforts of this type more visible and advance knowledge of effective strategies for cultural policy-related initiatives in contexts of urban sustainability.

The topic is also present in international political contexts through such initiatives as the United Cities and Local Governments 2010 policy statement "Culture: Fourth Pillar of Sustainable Development", The Hangzhou Declaration: "Placing Culture at the Heart of Sustainable Development Policies" (UNESCO, 2013 b) and a series of international congresses, meetings and reports (e.g., un System Task Team, 2012). Among recent efforts to include culture as an explicit goal in the post-2015 international development agenda, the commitment of a consortium of international networks of governmental and non-governmental organizations and global cultural actors ${ }^{1}$ is notable (see IFACCA et al., 2013). Collectively, these efforts are providing global visibility and leadership in addressing this issue. They are also creating places where diverse knowledge and case studies have been brought forward to demon-

1. The lead organizations are: International Federation of Arts Councils and Cultural Agencies, United Cities and Local Governments - Committee on Culture, International Federation of Coalitions for Cultural Diversity, and Culture Action Europe. 
strate the importance of integrating cultural considerations in sustainable development projects, policy and programmes.

As mentioned previously, multifaceted conceptual currents are informing these developments. Although research on the cultural dimension of sustainable development is lagging behind other sustainability-related research, the pace of scholarly attention to this issue is accelerating. Many research initiatives, policy/planning efforts and artistic projects are illuminating the complexity of the connections between culture and sustainability, articulating how culture is a driver and enabler of sustainable development and a foundation for transition to a truly sustainable society. Within this complex and dynamic knowledge milieu, culture is understood as 'a way of life' and also addressed through more narrow definitions focusing on culture-based expressions and ideas, activities and innovative approaches. The complexity of storylines and approaches in the research literature indicates that thinking about cultural sustainability is transdisciplinary in nature and at an early conceptual stage (Soini \& Birkeland, forthcoming).

At this time, one can view the inclusion of culture in sustainability as a paradigm-change-in-process, still in the process of elaboration (Duxbury, Cullen \& Pascual, 2012). A "cultural theory of sustainable urbanization" (Nadarajah \& Yamamoto, 2007: 11) has not yet developed, but there is a growing consensus that "understanding sustainability processes requires an understanding of cultures" (Meuleman, 2013: 49). Progress has been observed in many small steps - in municipal plans, citizen dialogues, reports and studies, artist and social grassroots experiments, critiques of unsustainable practices and a widely shared conviction of the need to include cultural dimensions in sustainability policy, planning and development initiatives. As Pieterse (2011) remarks, "It will be in the messy efforts to implement alternatives that more robust theoretical frames will crystallize and, in turn, spawn a more effective praxis" (p. 315).

\section{Strategic Directions:Three Dimensions of Cultural Governance}

Governance is concerned with policy processes - "the means by which policy objectives and approaches are identified, selected and implemented" 
(Gattinger, 2011: 4). Among multiple definitions, governance generally focuses on "coordination within and between government, business and societal actors to pursue shared or interdependent objectives when resources, power and information are widely distributed between them and no single actor can effectively pursue the objectives on their own" (p. 3). There is a rapidly growing literature on governance of sustainability and an adequate review and synthesis of this research is beyond the scope of the current paper. However, based on policy/planning-linked research and practice-based innovations internationally, a cultural governance framework for culture within the context of sustainable development could contain three main interrelated dimensions:

1. Culturally sensitive sustainability governance processes and structures.

2. A cultural framework or lens on all public policies/decisions.

3. A sustainability approach to cultural policy/planning and governance.

\section{Culturally Sensitive Sustainability Governance Processes and Structures}

In Transgovernance: Advancing Sustainability Governance, Louis Meuleman (2013) observes that existing governance frameworks seem to deny the social complexity and uncertainty of our contemporary world and argues that "sustainability governance should be more culturally sensitive, reflexive and dynamic" (p. 37). The focus here is on process: Meuleman notes that culturally sensitive sustainability governance requires permanent and systematic attention to translate or adapt possible solutions into ones that work well in a given cultural setting. A "culturally sensitive metagovernance for sustainable development" requires "institutions, instruments, processes, and actor involvement based on compatibility of values and traditions rather than on commonality or integration" (p. 37). A cultural assessment within a sustainability governance framework would ask: "What are key values linked to both the objectives of sustainability and of the problematique, and how can they be reconciled? Simply put, how can they be made compatible?" (p. 70). 
Meuleman (2013: 69-70) suggests a series of governance principles that could be useful for the design of culturally sensitive institutions and transformation processes for sustainability: reflexivity, resilience, transparency, inclusiveness, problem-orientedness as a point of departure, temporality, locality, potential for diversity, culturality, polycentricity and historicity. ${ }^{2}$ Along these lines, UNESCO has designed a cultural diversity lens "to create awareness of cultural dimensions in development programmes (including development projects, policies and strategies)" (UNESCO 2013 a: no page).

\section{A Cultural Framework or Lens on All Public Policies/Decisions}

Although related, a distinction is made here between a cultural sensitivity to facilitate compatibility and acceptance of externally devised programmes (above) and a more endogenous review process to ensure internally defined development proceeds in harmony with local cultural contexts and priorities (this section). The idea of a cultural lens on all public policies and plans is rooted in practices developed in regards to potential impacts on aboriginal cultures. In New Zealand, for example, Cultural Impact Assessments (CIA) are prepared as technical reports, similar to other technical reports such as ecological or hydrological assessments, documenting "Māori cultural values, interests and associations with an area or a resource, and the potential impacts of a proposed activity on these" (Quality Planning, 2012: 2). It is also a tool to "facilitate meaningful and effective participation of Māori in impact assessment” (p. 2). A variation of a Cultural Impact Assessment is a Cultural Values Report (CVR) to "identify and describe values pertaining to an area or resource" (p. 2). CVR may address "broad level impacts of development occurring or anticipated" in an area and "provide direction as to the relevant issues and how these should best be addressed" rather than describing effects relating to a specific activity (p. 2). Although these reports are not required by statute, an assessment of impacts on cultural values and interests assists both developers and local authorities to meet a variety of statutory obligations (Quality Planning, 2012).

2. Further elaboration of these principles, while beyond the scope of this article, would be a valuable contribution to advancing this objective. 
The idea of expanding such cultural assessments to all community development actions and policy has been discussed for over a decade. In The Fourth Pillar of Sustainability: Culture's Essential Role in Public Planning, Jon Hawkes (2001) argued that government must develop a framework that evaluates the cultural impacts of all environmental, economic and social decisions and plans being implemented in cities and communities. This cultural lens goes beyond a focus on professional arts production to incorporate a broader view of culture: "the social production of meaning" or "making sense together"- a focus on process rather than product (Hawkes, 2013:2). Elaborating, he explains: "The way a society governs itself cannot be fully democratic without there being clear avenues for the expression of community values, and unless these expressions directly affect the directions society takes. These processes are culture at work" (p. 2). In order for public planning to be more effective, he argues, its methodology should include "an integrated framework of cultural evaluation along similar lines to those being developed for social, environmental and economic impact assessment" (p. 2). Hawkes (2013: 2-3) proposes four elements of a mandatory cultural framework to be applied to all public planning:

- Active participation - What has been the quality of community input into the development of the actual and proposed activities under review?

- Diverse authenticity - To what extent are these activities reflective of the values and ways of life of the communities upon which they (will) impact?

- Continuing engagement - Do these activities improve the capacity of communities to act and interact?

- Resonance with 'universal' values -Are human rights respected, including cultural rights?

Additional examples: IFACCA (2013) advocate that development-related policy frameworks and action plans "should provide a common 'Cultural Impact Assessment' mechanism to be used in urbanization processes and aim at improving the cultural quality of public spaces" (p. 9). Similarly, in 
the context of rapid urban development in South Korea, Choi and Ahn (2013) argue that planning and development processes need to give value to the "soft tissues" within the built environment, defined as "the sustenance and evolution of local resources and values rooted in culture and history" and "an integrated understanding of ... perceptions of the cultural and social contexts" (p. 55).

Including a cultural lens in all urban development decisions and processes is still a challenge. Research on the Canadian ICSP development process suggests the inclusion of culture within city planning is gradually advancing, but integration of cultural considerations within a holistic sustainability planning paradigm has not yet been achieved (Duxbury \& Jeannotte, 2012). Beginning steps can be seen in the inclusion of cultural considerations in local sustainability policies, plans and related documents.

The initial report from the 2013 World Cities Culture Forum, a snapshot of the general state of urban cultural policy in the world's major cities, admits that culture is not yet a cornerstone of city development and the integration of culture within broader city development processes and policy areas is still considered an emerging practice. On one hand, the report advises cultural professionals to "come out of their own sectors and departments and be prepared to engage across city government" and collaborate, allowing for a multiplicity of competing priorities (p. 5). On the other hand, resistance is also experienced in the broader sphere of urban planning, often characterized by entrenched interests and resistance to rethinking sustainability to incorporate concerns of cultural development (Duxbury, Cullen \& Pascual, 2012). Altogether, silo-policy thinking and operational challenges in practice tend to block the development of a 'cultural lens' on all city policies and development decisions.

\section{A Sustainability Approach to Cultural Policy/Planning and Governance}

Informed by research literature on sustainability governance and ongoing analysis of a variety of culture-based case studies internationally, this section envisions some broad contours for thinking about and building cultural governance systems in the context of sustainable urban development. It rep- 
resents research in process and aims to outline some ideas about the elements and dynamics that might be incorporated, but is not meant to be a comprehensive profile. Future work will compare leading urban cultural governance models with evolving thinking about sustainability governance.

Overall, a sustainability approach to cultural governance embraces a collaborative approach to how cultural policy/governance is directed and functions and incorporates an iterative planning process like the transition management approach described earlier. Cultural governance is based on a systems view of culture, knowledgeable about how various cultural elements operate and are sustained locally, favours organic growth over large-scale developer-led projects and incorporates a long-term perspective. In a context of openness, the system aims to highlight and privilege local cultural values, knowledge and distinctiveness in order to address goals such as enriching and valourizing public spaces, making them platforms for social and cultural actions and for environmental awareness, and reflecting local cultures in their design. All efforts support "the possibility of diversity, difference and local contingency rather than the imposition of global homogeneity" (NSFwUs, 2000: 7) and consider global urban development trends through this local lens.

Cultural governance systems in a sustainability context aim to nurture cross-sector relationships and build "enriched platforms" for dialogue and action (Silver, 2013). The centrality of relations in this context implies a governance imperative to bridge different sectors, transcend conventional dualisms (NSFWUS, 2000) and activate common goals as points for cooperation, coordination of actions and partnerships. Activities and strategies aim to provide diverse (democratized) artistic programming for all citizens, to build bridges among people and to diminish inequities and social divides, prioritizing engagement with "hard-to-reach communities" (WCCF, 2013: 4). Governance systems are open to emerging practices of citizen-driven collaborations and alternatives and to new priorities, informed by both economic and 'softer' aesthetic and ethical values, and linked to broader civic agendas (e.g., youth engagement).

Planning processes embrace genuine community engagement processes and local authorities commit to work with cultural agents from the outset of planning processes, not as an afterthought, and not 'dictated to' (WCCF, 2013). 
Approaches are sensitive to multifaceted, localized contexts and the diversity of pathways that may be taken to integrate cultural considerations within public measures relating to local sustainability. Attention to scale allows for neighbourhood or community-scale decentralization as well as urban system network-level infrastructure, as most appropriate (Pieterse, 2011). Governance systems foster flexible and ongoing processes (NSFWUS, 2000) and develop in situ, emergent systems of arrangements and strategies (vs. tight plans) in which an array of policy/planning approaches and mechanisms may be employed to support artistic/cultural activities as a driver and enabler of practices toward sustainable development.

Interlinking these local cultural governance systems, an international knowledge meta-system supports and informs local action (i.e., filtered through local concerns, priorities and conditions), shares learning and experiences and collectively evolves thinking and practice/praxis.

\section{Closing Reflections}

When the avenues for culture within urban sustainability are not evident or not recognized within a governance system, culture tends to be sidelined in policy and planning contexts (Duxbury \& Jeannotte, 2012). In order to advance the inclusion of culture within urban sustainability frameworks, collective action is necessary to build on conceptual and experimental practice-based foundations and put forward principles and operational strategies for cultural governance systems that would be sympathetic and coherent within evolving thinking about strategies for more sustainable cities and communities. From this perspective, this paper aimed to envision and sketch out the contours of what a system of cultural governance might look like within a sustainable city context. Three key dimensions were proposed: culturally sensitive sustainability governance processes and structures, a cultural lens on all public policies/decisions and a sustainability approach to cultural policy/planning and governance.

The continued general lack of integration of culture in wider urban planning and development, as highlighted by the World Cities Culture Forum 2013 report, stands as a reminder of the sizable challenge of this goal. Yet the numerous actions, policies, programmes and experimental initiatives underway 
in communities of all sizes may collectively evolve a new way of perceiving connections and roles for cultural approaches and activity in transforming our cities into more sustainable living environments. Informed by a burgeoning transdisciplinary research literature examining the complex linkages between culture and sustainability, the continued elaboration of these practices will, over time, contribute to the development of more culturally and context-sensitive policies for sustainable development.

To systematize these approaches and innovate a renewed approach to cultural governance in the context of urban sustainability, the six stages of social innovation (Murray, Caulier-Grice \& Mulligan, 2010) are useful to consider:

1. Diagnosis - highlighting emerging problems.

2. Fostering creative methods to generate ideas and proposals.

3. Designing prototypes and implementing pilot experiments enabling ideas to be tested.

4. Achieving sustainability in the long term, making practice part of the routine.

5. Disseminating and generalizing large-scale innovation.

6. Causing systematic change.

At this point in time, the inclusion of culture in the planning and building of more sustainable cities tends to exist within the first three stages. The challenge now is to climb the remaining stages, a process to be advanced locally through innovations in city planning/development systems, creative cooperative arrangements and local experiments, and globally through trans-local knowledge sharing, analysis and co-learning.

\section{References}

Blandy, D. and J. FenN (2012): «Sustainability: Sustaining Cities and Community Cultural Development», Studies in Art Education, 53(4): pp. 270-282. 
Camponeschi, C. (2013): Enabling City: Enhancing Creative Community Resilience, Vol. 2. Retrieved Nov. 23, 2013, from www.enablingcity.com.

Chol, H. S. and K. H. Ahv (2013): «Assessing the Sustenance and Evolution of Social and Cultural Contexts within Sustainable Urban Development, Using as a Case the MAC in South Korea», Sustainable Cities and Society, 6: 51-56.

Duxbury, N. (ed.) (2013): Animation of Public Space through the Arts: Toward more Sustainable Communities, Almedina, Coimbra.

Duxbury, N. (2014): «Culture and Sustainability: How New Ways of Collaboration Allow Us to Re-think our Cities [English] / Cultura y sostenibilidad: Cómo las nuevas formas de colaboración permiten replantearnos nuestras ciudades [Spanish]», Observatorio Cultural (Cultural Observatory), National Council for Culture and the Arts of Chile, Santiago.

Duxbury, N.; C. Cullen and J. Pascual (2012): Cities, Culture and Sustainable Development. In ANHEIER, H. K.; Y. R. Isar and M. HoelsCHER (eds.): Cultural Policy and Governance in a New Metropolitan Age (pp. 73-86), The Cultures and Globalization Series, Vol. 5. Sage, London.

Duxbury, N. and M. S. Jeannotte (2011): «Introduction: Culture and sustainable communities», Culture and Local Governance, 3(1-2): 1-10. Special issue on «Culture and Sustainable Communities».

- (2012): «Including Culture in Sustainability: An Assessment of Canada's Integrated Community Sustainability Plans», International Journal of Urban Sustainable Development, 4(1): 1-19.

GatTinger, M. (2011): «Democratization of Culture, Cultural Democracy and Governance». Paper presented at the Canadian Public Arts Funders Annual General Meeting, 16-18 November 2011, Whitehorse, Yukon. <http://www.cpaf-opsac.org/en/themes/documents/ CPAF_2011_AGM_Democratization_of_Culture_Cultural_Democracy Governance Mar082012 000.pdf $>$ [2/2/2014].

Girard, L. F. (2011): «Creativity and the Human Sustainable City: Principles and Approaches for Nurturing City Resilience». In GIRARD, L. F.; T. Baycan and P. NiJKamp (eds.): Sustainable City and Creativity: Promoting Creative Urban Initiatives, pp. 55-96, Ashgate, London.

Hawkes, J. (2001): The Fourth Pillar of Sustainability: Culture's Essential Role in Public Planning, Common Ground, Melbourne.

Hawkes, J. (2013): «Shaping policies: Culture-sensitive and context-based policies in sustainable development». Address at the Hangzhou In- 
ternational Congress, «Culture: Key to Sustainable Development», 15-17 May 2013, Hangzhou, China.

Hicks, L. E. and R. King (2007): «Guest Editorial: Confronting Environmental Collapse: Visual Culture, Art Education, and Environmental Responsibility», Studies in Art Education, 48(4): 332-335.

International Federation of Arts Councils and Cultural Agencies (ifaCca); United Cites and Local Governments - Committee on Culture, International Federation of Coalitions for Cultural Diversity and Cultural Action Europe (2013): Culture as a Goal in the Post-2015 Development Agenda. $<$ http://media.ifacca. org/files/cultureasgoalweb.pdf> [30/11/2013].

International Social Science Council (ISSc) (2013): World Social Science Report: Changing Global Environments. Paris: ISSC, UNESCO \& OECD. $<\underline{\text { http://www.worldsocialscience.org/activities/world-social-sci- }}$ ence-report/the-2013-report/> [30/11/2013].

Jeannotte, M. S. and N. Duxbury (2012): «Culture and Sustainability: Experts and Amateurs in the Development of Integrated Community Sustainability Plans», Canadian Journal of Media Studies, Fall, 141-175. Special issue on «Experts and amateurs in communication and culture». <http://cjms.fims.uwo.ca/issues/special/index.html> [3/1/2014].

Jordan, A. (2008): «The Governance of Sustainable Development: Taking Stock and Looking Forwards», Environment and Planning C: Government and Policy, 26(1): 17-33.

Kirchberg, V. and S. Kagan (eds.) (2013): City, Culture and Society, 4(3). Special issue on «The Sustainable City and the Arts».

Meuleman, L. (2013): «Cultural Diversity and Sustainability Metagovernance». In L. Meuleman (ed.): Transgovernance: Advancing sustainability governance. Springer.

Miles, M.(2013): «APost-Creative City?», RCCSAnnual Review, no. 5, 123-139. $<$ http://rccsar.revues.org/458> [30/11/2013].

Murray, R.; J. Caulier-Grice and G. Mulligan (2010): The Open Book of Social Innovation, The Young Foundation \& THE LAB - NESTA, London.

Nadarajah, M. and A. T. Yamamoto (eds.) (2007): Urban crisis: Culture and the Sustainability of Cities, United Nations University Press, Tokyo.

Newig, J.; J.-P. Voss and J. Monstadt (2007): Editorial: «Governance for Sustainable Development in the Face of Ambivalence, Uncertainty 
and Distributed Power: An Introduction», Journal of Environmental Policy \& Planning, 9(3): 185-192.

National Science Foundation Workshop on Urban Sustainability (nsFwus) (2000): Towards a Comprehensive Geographical Perspective on Urban Sustainability. Final report of the 1998: National Science Foundation Workshop on Urban Sustainability. Rutgers University.

Pieterse, E. (2011): «Recasting Urban Sustainability in the South», Development, 54(3): 309-316.

Quality Planning (2012): Consent Support Guidance Note: FaQ's about Cultural Impact Assessments. The RMA Quality Planning Resource, managed by New Zealand Planning Institute. $<$ http://www.qualityplanning.org.nz/index.php/supporting-components/faq-s-on-cultural-impact-assessments $>$ [3/1/2014].

SANDercock, L. (2003): Cosmopolis II: Mongrel Cities in the 21st Century, Continuum, London.

Shaharir, B. M. Z. (2012): A New Paradigm of Sustainability. Journal of Sustainable Development, 5(1): 91-99.

Silver, D. (2013): «Local Politics in the Creative City: The Case of Toronto». In C. Grodach \& D. Silver (eds.): The politics of urban cultural policy: Global perspectives, pp. 249-265, Routledge, Oxon, UK.

SoINI, K. and I. BIRKELAND (forthcoming): Exploring the Scientific Discourse on Cultural Sustainability. Geoforum.

UnesCo [2013 a]: The cultural diversity lens. $<$ http://www.unesco.org/new/ en/culture/themes/culture-and-development/the-cultural-diversity-lens/> [3/1/2014].

UnesCo (2013 b): The Hangzhou Declaration: Placing Culture at the Heart of Sustainable Development Policies, unesco, Adopted in Hangzhou, People's Republic of China, May 17, 2013, Paris.

Un System Task Team on the Post-2015 Un Development Agenda (2012): Culture: A Driver and an Enabler of Sustainable Development, uNESCO, Paris. <https://en.unesco.org/post2015/sites/post2015/files/ Think\%20Piece $\% 20$ Culture.pdf $>$ [3/1/2014].

United Cities and Local Governments (UClg) (2010): Culture: Fourth pillar of sustainable development. Policy Statement approved by the UCLG Executive Bureau, Mexico City, Nov. 17, 2010.

Voss, J. P.; A. Smith and J. Grin (2009): «Designing Long-Term Policy: Rethinking Transition Management», Policy Sciences, 42(4): pp. 275-302. 
World Cities Culture Forum (wccF) (2013): The New Cultural Agenda: Beyond Boosterism. Policy Briefing 1: Istanbul Summit 2013, воР Consulting \& Mayor of London, London. 